\title{
"COOPERACIÓN INTERNACIONAL PARA EL DESARROLLO: GOBIERNO, ECONOMÍA Y SOCIEDAD. EVOLUCIÓN DE LAS POLÍTICAS Y ESCENARIOS FUTUROS"
}

\author{
de Carlo Tassara. \\ Ediciones Unisalle, Bogotá, 2016 \\ por Alessandra Urzi \\ Universidad de Roma La Sapienza (Italia)
}

Las vibrantes dinámicas de cambio que se han producido en los últimos treinta años en la geografía del desarrollo, han sumamente influido en la redefinición de los desafíos y de las responsabilidades globales. Las dinámicas de globalización, de redistribución del poder entre actores estatales y la diversificación de los actores no estatales que participan en los procesos de desarrollo, alteran las jerarquías y los equilibrios internacionales, articulando nuevas formas de relaciones Norte-Sur. Estos elementos han concurrido en determinar la configuración multipolar del sistema de relaciones internacionales actual.

Por ende, las nuevas políticas de desarrollo configuran escenarios inéditos en la construcción de alianzas internacionales para la lucha contra la pobreza y la cohesión social, así como la consolidación de un diálogo participativo entre pares y la implementación de estrategias de carácter global, previa apropiación y ajuste al contexto local. A pesar de la introducción de esquemas innovadores de cooperación y de la atención a la trasparencia de la ayuda, persisten numerosos interrogantes sobre la eficacia que las medidas adoptadas pueden generar con respecto a los importantes desafíos de la gobernanza global. Por otro lado, hay que tener en cuenta algunos factores que dificultan la consolidación de esta nueva proyección de la cooperación, como por ejemplo los enfoques neo-nacionalistas y proteccionistas, a veces caracterizados por tintes autoritarios y hasta xenófobos, que en los últimos años han ganado terreno en varios países y regiones del planeta.

Sobre la base de estos fundamentos, la obra "Cooperación internacional para el desarrollo: gobierno, economía y sociedad. Evolución de las políticas y escenarios futuros ${ }^{1}$ " de Carlo Tassara, brinda una valiosa contribución al análisis de la coyuntura contemporánea y de las posibles perspectivas futuras para la cooperación para el desarrollo.

El estudio persigue dos itinerarios: por un lado ofrecer elementos para comprender las 
razones y los procesos que han determinado la configuración hodierna del sistema de relaciones internacionales y las consiguientes características de la cooperación para el desarrollo. Por otro lado, analizar los posibles escenarios futuros en materia de implementación de políticas de cooperación, que determinarán la esencia de las respuestas de la comunidad internacional a los problemas globales.

El autor es Carlo Tassara: catedrático de la Universidad de Roma La Sapienza, experto en relaciones euro-latinoamericanas y docente de posgrado en Colombia, se desempeña también como asesor de políticas sociales para entidades públicas, organizaciones internacionales y actores no estatales. Su doble sensibilidad, académica y técnica, y sus treinta y cinco años de experiencia, le permiten conjugar una observación crítica y un enfoque realista en una continua exploración de soluciones eficaces a largo plazo.

La publicación de su última labor, llega un año después de la formulación de los Objetivos de Desarrollo Sostenible (ODS), cuyo horizonte temporal se extiende hasta 2030. Estas metas, no vinculantes aún, empujan a los gobiernos y los actores internacionales en la implementación de una agenda común que aborda problemas de interés colectivo: la lucha contra la pobreza y la seguridad alimentaria, la inclusión social y la paridad de género, la sostenibilidad ambiental, la construcción de relaciones pacíficas, así como la reducción de la disparidad económica mundial.

El carácter universal que califica estos nuevos objetivos, desafía la comunidad internacional en remodelar a todo nivel sus políticas públicas, según criterios de apropiación, alineación y armonización, y así crear las condiciones propicias para lograr las metas establecidas.

A partir de la inauguración de este nuevo ciclo de políticas globales, el autor se propone interpretar la agenda de desarrollo a la luz de los principales cambios que caracterizan la escena mundial actual.

La aproximación histórica adoptada en el volumen, reconstruye las diferentes interpretaciones que se han dado sobre el concepto de desarrollo, así como individua las razones, las fuerzas motrices y los intereses que han impulsado la adopción, en función de cada caso, de específicas políticas de desarrollo. Esta perspectiva es indispensable para reflexionar sobre cómo los programas han sido dictados por el contexto no solo económico, sino también políticos, social, cultural y ético. En efecto, a pesar de los aportes innovadores que han afectado la evolución del concepto de desarrollo, y así sus aplicaciones, frecuentemente las medidas de ayuda no han sido acompañadas por estrategias dialógicas, sino más bien han basado sus raison d'être sobre específicos intereses, que han marcado cada época.

Esta tensión, aún en nuestros días, corre el riesgo de caracterizar la ayuda al desarrollo, si las declaraciones de intenciones no serán acompañadas por una constante búsqueda de coherencia en las estrategias que, precisamente por su calidad universal, requieren un enfoque coordinado de políticas sociales, medioambientales, laborales, fiscales, migratorias y de seguridad.

Lo que se desprende de la obra es que el peso creciente de nuevas formas de cooperación horizontal, como la cooperación Sur-Sur y triangular, amplía el abanico de los actores involucrados y de las posibles soluciones, alterando la clásica relación jerárquica entre donantes y receptores. Esto, si puede generar algunos temores de excesiva descentralización, abre espacios de intercambio y diálogo para movilizar nuevas formas de cooperación regional y global.

Como destaca en el Prólogo del libro José Antonio Ocampo, Presidente del Comité del Políticas Publicas de Desarrollo de la 
Organización de las Naciones Unidas, subsisten algunos riesgos de incurrir en lo que él denomina la "paradoja de la soberanía". De hecho, aun si hoy en día está generalmente reconocido que cada nación no puede enfrentar en autonomía los problemas de carácter global, al mismo tiempo permanece una fuerte dificultad en sobrepasar el tradicional concepto de soberanía y aceptar la necesaria coordinación a nivel internacional en la formulación de estrategias comunes. Según Tassara, a cambio de dichas dificultades el único recorrido posible es implementar la nueva agenda global según criterios de apropiación, de manera que las responsabilidades puedan ser tomadas según cada condición, pero también en conformidad a principios éticos y normativos de alcance universal. El autor señala, por consiguiente, los posibles escenarios que podrían surgir de la implementación de la agenda post 2015. Entre estos, cabe esperar la creación de sinergias, como por ejemplo entre la Unión Europea y la Comunidad de Estados Latinoamericanos y del Caribe, que en la actualidad apuntan a diferentes direcciones, pero que coordinando conjuntamente sus esfuerzos, podrían incidir considerablemente en la agenda internacional. Este planteamiento atañe a la necesidad de crear las condiciones óptimas para lograr el cumplimiento de los ODS por medio de recursos apropiados y de la calidad de las medidas adoptadas.

El hilo conductor de la obra es un incesante preguntarse sobre cómo las dinámicas de cambio que caracterizan la cooperación para el desarrollo afectan y afectarán los desafíos que está enfrentando la comunidad internacional (y que tendrá que enfrentar de manera más contundente en el futuro cercano). La mirada crítica adoptada es necesaria para comprender las dinámicas actuales y tiene en cuenta las necesidades del lector, escudriñando temas transversales a todos los sectores de la cooperación. Con respecto a los asuntos sobresalientes, el autor trata constantemente de ofrecer una visión exhaustiva destacando oportunidades y amenazas de los cambios identificados. Esta continua tensión entre impactos positivos y negativos restituye el sentido de complejidad que caracteriza la cooperación internacional que, sobre todo en la coyuntura actual, y resulta fundamental en determinar las estrategias de la agenda mundial.

Este libro, plataforma indispensable para plantear útiles interrogantes, es una herramienta para la enseñanza a quienes se acercan por primera vez al mundo de la cooperación, así como un valioso estímulo a la reflexión para profesionales y técnicos del sector que están interesados en consolidar su pensamiento crítico sobre los problemas más actuales de la gobernanza global.

De la lectura del texto se desprende que, únicamente con la voluntad de encontrar la justa alquimia entre los diferentes enfoques, se pueden generar formas de multilateralismo efectivo para la adopción de políticas coordinadas.

El reto para el futuro parece ser el de concebir un modelo de políticas públicas coherentes entre si y dirigidas a enfrentar las exigencias que no abarcan solo los países en desarrollo, sino toda la humanidad. El camino parece aún largo, pero la preciosa contribución de Carlo Tassara permite desanudar algunos temas relevantes y de gran actualidad, ofreciendo interesantes elementos de reflexión. 


\section{NOTA}

2381 Más información disponible en http://ebooks. lasalle.edu.co/product/cooperacin-internacionalpara-el-desarrollo

\section{PARA CITAR ESTE ARTÍCULO:}

Urzi, A. (2017). "Reseña bibliográfica: Cooperación internacional para el desarrollo: gobierno, economía y sociedad. Evolución de las políticas y escenarios futuros, de Carlo Tassara", DAAPGE, año 17, № 28 (ene-jun), 2017, pp. 235-238. Santa Fe, Argentina: UNL. 